\title{
A IMPOSSIBILIDADE DE LEGALIZAÇÃO DO ABORTO NO BRASIL
}

\author{
Quésia Falcão de Dutra ${ }^{1}$
}

\begin{abstract}
RESUMO: O presente trabalho tem por objetivo o estudo do tratamento constitucional e legal sobre o direito à vida, confrontando-o com a possibilidade ou não de legalização do aborto no Brasil. Pretende-se o tratamento do tema dissociado de posições religiosas ou filosóficas e, na medida do possível, científicas. Utiliza-se o método de pesquisa bibliográfica no presente trabalho. Inicia-se pelo estudo do tratamento legal e jurisprudencial do aborto no Brasil. Posteriormente, analisa-se a polêmica da definição do momento em que se inicia a vida e qual seria a corrente adotada no Brasil. Por fim, confrontam-se os dados obtidos para se chegar à conclusão de que é impossível a legalização do aborto no Brasil, tanto por lei infraconstitucional, como por emenda constitucional.
\end{abstract}

PALAVRAS-CHAVE: Aborto; Legalização; Direito à Vida.

\section{The impossibility of the legalization of abortion in Brazil}

\begin{abstract}
The present paper aims to study the constitutional and legal treatment concerning the right to life, confronting it with the possibility to legalize or not the abortion in Brazil. It intends the treatment of the theme dissociated of religious or philosophical positions and, whenever possible, scientific. It uses the method of bibliographic search in this paper. It begins by studying the legal and jurisprudential treatment of abortion in Brazil. Posteriorly, it analyzes the controversy of the definition of the moment at which life is created and what would be the chain adopted in Brazil. Finally, it confronts the data obtained to achieve the conclusion that it is impossible to legalize the abortion in Brazil, by infra-constitutional law as well as by constitutional amendment.
\end{abstract}

KEY-WORDS: Abortion; Legalization; Right to Life.

\section{INTRODUÇÃO}

Apesar de criminalizada, a prática do aborto tem sido crescentemente realizada em nosso país. Isto se deve a muitos fatores, podendo ser apontados como principais: o aumento do número de gravidez indesejada pelo desconhecimento ou negligência na utilização dos métodos contraceptivos e a facilidade na aquisição de substâncias abortivas e acesso a clínicas clandestinas de aborto.

\footnotetext{
${ }^{1}$ Advogada, inscrita na OAB/SC sob o n. 29.782-B. Graduada em Direito pela Universidade Federal de Santa Maria (UFSM).
} 
Diante desses dados, a sociedade civil e os órgãos legislativos constantemente levantam debates sobre o tema, nos quais uma das soluções propostas para o problema é a legalização plena do aborto.

Entretanto, é necessário verificar se, diante da norma máxima do ordenamento jurídico pátrio, a Constituição da República Federativa do Brasil, e de tratados internacionais de direitos humanos ratificados pelo país, é possível a legalização da prática abortiva.

É justamente desta problemática que cuida o presente trabalho.

\section{TRATAMENTO LEGAL E JURISPRUDENCIAL DO ABORTO NO BRASIL}

A Constituição Federal consagra, no caput do seu artigo $5^{\circ}$, o direito à vida como fundamental dos indivíduos. Por óbvio, sem o reconhecimento do direito de viver, a estipulação de qualquer direito do homem seria destituída de sentido.

E mais, a Constituição reconhece o direito de ter uma existência digna como fundamento da República Federativa do Brasil, em seu artigo $2^{\circ}$, inciso III.

Pode-se perceber que qualquer forma de privação do direito à vida é vedada pela Constituição, ressalvadas raras exceções, como nos casos de pena de morte em situação de guerra declarada ou o reconhecimento da legítima defesa.

Tendo em vista o comando constitucional, o Código Penal, dentro do capítulo que trata dos crimes contra a vida, criminaliza o aborto provocado pela gestante ou com o seu consentimento e o aborto provocado por terceiro.

Nos casos de aborto provocado pela gestante ou por terceiro com o seu consentimento, o artigo 124 do Código Penal prevê a aplicação da pena de detenção, de um a três anos.

Já o terceiro que provoca o aborto fica sujeito à pena de reclusão de três a dez anos, se o faz sem o consentimento da gestante, conforme preceitua o artigo 125 do Código Penal, ou à pena de reclusão de um a quatro anos, caso haja com consentimento da gestante, consoante determina o artigo 126 do Código Penal.

Contudo, mesmo que exista consentimento da gestante, se esta não for maior de quatorze anos, tiver problemas mentais ou se o seu consentimento for obtido mediante fraude, grave ameaça ou violência, a pena aplicada é a mesma do crime de aborto em terceiro sem consentimento. 
Além disso, nos casos de aborto realizado por terceiros, com ou sem consentimento, as penas cominadas são aumentadas de um terço, se a gestante sofrer lesões corporais graves em virtude do aborto ou dos meios nele empregados, ou duplicadas, caso a gestante venha a falecer por estas causas.

Determina, ainda, o artigo 128 do Código Penal, que o aborto praticado por médico não é punido se não houver outro meio de salvar a vida da gestante (aborto necessário) ou se a gravidez resultar de estupro (aborto sentimental), havendo consentimento da gestante ou de seus representantes legais, se for incapaz. São os chamados casos de aborto terapêutico.

Aliado a estes casos, a jurisprudência consagrou um terceiro caso de aborto terapêutico. Trata-se do caso de aborto de feto anencéfalo.

A questão está sendo discutida no Supremo Tribunal Federal, na Ação de Descumprimento de Preceito Fundamental n. 54, ajuizada pela Confederação Nacional dos Trabalhadores de Saúde, a qual tem como pedido a interpretação conforme a Constituição dos dispositivos do Código Penal acima mencionados, para que seja declarada a sua não incidência nos casos de aborto de fetos anencefálicos.

De acordo com Marcelo Novelino (2008), a arguição possui três argumentos básicos, saber:

$1^{\circ}$ ) antecipação terapêutica do parto não é aborto (atipicidade da conduta): " a morte do feto, nesses casos, decorre da má formação congênita, sendo certa e inevitável, ainda que decorridos os nove meses normais de gestação. Falta à hipótese o suporte fático exigido pelo tipo penal”; $2^{\circ}$ ) ainda que se considerasse a antecipação terapêutica como aborto, ela não seria punível (interpretação evolutiva do Código Penal): “a hipótese aqui em exame só não foi expressamente abrigada no art. 128 do Código Penal como excludente de punibilidade porque em 1940, quando editada sua Parte Especial, a tecnologia existente não possibilitava o diagnóstico preciso de anomalias fetais incompativeis com a vida”; $3^{\circ}$ ) dignidade da pessoa humana, analogia à tortura e interpretação conforme a Constituição: "impor à mulher o dever de carregar por nove meses um feto que sabe, com plenitude de certeza, não sobreviverá, causando-lhe dor, angústia e frustração, importa violação de ambas as vertentes da dignidade humana (...)”. (NOVELINO, 2008, p. 267). 
A ação citada se encontra pendente de julgamento no Supremo Tribunal Federal, havendo sido concedida liminar nos autos para suspender processos criminais em curso que tratem de interrupção de gravidez em casos de anencefalia.

Resta esperar para saber qual será a posição adotada pelo Supremo Tribunal Federal, se pela descriminalização do aborto de fetos anencefálicos ou não.

Verificados os pontos principais do tratamento do aborto pela Constituição Federal e jurisprudência pátria, necessário será o estudo das teorias sobre o início da vida tutelada pelo ordenamento jurídico.

\section{A POLÊMICA DEFINIÇÃO DO MOMENTO EM QUE SE INICIA A VIDA}

A definição do momento exato em que a vida se inicia é tortuosa para cientistas da medicina, religiosos, filósofos e, consequentemente, para os estudiosos e operadores do Direito.

Não se pretende neste estudo abordar as questões religiosas ou filosóficas que envolvem a temática da legalização do aborto. Também não é objeto do presente trabalho a análise minuciosa do tratamento que a medicina confere ao tema. Apenas se pretende tratar das teorias científicas que dispõem acerca do início da vida para proporcionar o adequado entendimento das disposições legais sobre a proteção da vida.

Cientificamente, existem, pelo menos, quatro teorias principais que são apontadas pelos doutrinadores para definir a partir de que momento o direito à vida passa a ser inviolável nos termos da Constituição Federal, as quais serão apontadas a seguir.

Destaca-se a teoria da fecundação ou concepção que entende ter início a vida com a fecundação do óvulo pelo espermatozoide, formando-se o zigoto.

Esta teoria foi adotada pela Convenção Americana de Direitos Humanos, internalizada no Brasil pelo Decreto 678/92, situação que será tratada adiante.

Ainda, destaca Marcelo Novelino (2008, p. 263) a existência da teoria da nidação, a qual ocorre em um "período aproximado de sete a dez dias após a fecundação", no qual se observará "a fixação do zigoto no útero materno, dando início à gravidez".

Existe, ainda, a corrente científica que aponta a formação do sistema nervoso central como o momento em que se inicia a vida. Esta corrente defende que o início da 
vida deve ser coincidente com o marco da morte, que seria o término das atividades do sistema nervoso central.

Neste sentido, ressalta Marcelo Novelino que:

Apesar da inexistência em nosso ordenamento jurídico de um dispositivo legal específico estabelecendo o momento em que se inicia a vida humana, a Lei $n$. 9.434/97 permite a retirada de órgãos destinados a transplante após o diagnóstico de "morte encefálica" do doador. Se para a legislação brasileira a vida humana termina quando o sistema nervoso para de funcionar, é lícito concluir, a contrario sensu, que o seu início teria lugar apenas quanto este se formasse ou, pelo menos, começasse a se formar, o que ocorre por volta do décimo quarto dia após a fecundação. Neste sentido, o início da vida humana deveria ser protegido a partir da formação da "placa neural". (NOVELINO, 2008, p. 264).

O Conselho Federal de Medicina já se manifestou no sentido de que a vida humana começaria apenas com o desenvolvimento de placa neural, não podendo antes disto o pré-embrião ser considerado ser humano, mas apenas uma expectativa potencial de vida (NOVELINO, 2008, p. 264).

Ainda, existe a teoria que entende começar a vida quando o feto possui capacidade de existir sem a mãe, o que ocorre entre a vigésima quarta e a vigésima sexta semanas de gestação.

Como ressaltado, a Constituição Federal silencia acerca do momento em que ocorreria o início da vida que tutela, sendo imprescindível a análise de outros elementos legislativos para concluir-se a partir de que instante a vida passa a ser inviolável e, como consequência, quando a legalização da prática do aborto passa a ser inadmissível.

\section{IMPOSSIBILIDADE DE LEGALIZAÇÃO DO ABORTO NO BRASIL}

Em que pese a Constituição Federal não estabeleça qual o marco da vida, a Convenção Americana de Direitos Humanos, internalizada no Brasil através do Decreto $678 / 92$, em seu art. $4^{\circ}, 1^{\circ}$, estabelece que "toda pessoa tem o direito que se respeite sua vida. Esse direito deve ser protegido pela lei e, em geral, desde o momento da concepção. Ninguém pode ser privado da vida arbitrariamente”. 
Assim, observa-se que o tratado internacional em questão determina que a vida começa no ato da concepção e a partir deste momento é inviolável e deve ser respeitada, sendo impossível a legalização irrestrita do aborto.

Note-se que, de acordo com a decisão proferida pelo Supremo Tribunal Federal no Recurso Extraordinário 466.343-SP, os tratados internacionais de direitos humanos internalizados no Brasil sem procedimento de emenda constitucional possuem natureza hierárquica de normas supralegais, ou seja, inferiores às normas constitucionais, mas superiores às normais infraconstitucionais.

Veja-se, por oportuno, trecho do voto proferido pelo Ministro Gilmar Mendes nos autos do Recurso Extraordinário mencionado:

Parece mais consistente a interpretação que atribui a característica de supralegalidade aos tratados e convenções de direitos humanos. Essa tese pugna pelo argumento de que os tratados sobre direitos humanos seriam infraconstitucionais, porém, diante de seu caráter especial em relação aos demais atos normativos internacionais, também seriam dotados de um atributo de supralegalidade. Em outros termos, os tratados sobre direitos humanos não poderiam afrontar a supremacia da Constituição, mas teriam lugar especial reservado no ordenamento jurídico. Equipará-los à legislação ordinária seria subestimar o seu valor especial no contexto do sistema de proteção dos direitos da pessoa humana. (2009)

Sendo assim, uma lei ordinária ou complementar não poderia ser utilizada para legalizar o aborto, já que o Pacto de São José da Costa Rica, com natureza supralegal, defende a inviolabilidade da vida desde a concepção.

Dessa forma, observa-se que a utilização, a contrario sensu, da Lei n. 9434/97 para determinar o início da vida no momento da formação do sistema nervoso central não possui respaldo legal, devendo ser afastada, porquanto norma de caráter supralegal já define outro critério para constatação do início da vida.

Fica, entretanto, o questionamento acerca da possibilidade de legalização do aborto ou definição de outro momento como início da vida através de emenda constitucional. 
A Constituição Federal, em seu art. 60, parágrafo $4^{\circ}$, inciso IV, refere não ser possível sequer a deliberação de emenda tendente a abolir os direitos e garantias constitucionais, nos quais se insere o direito amplo e irrestrito à vida.

A doutrina e jurisprudência asseveram que não é possível a deliberação de propostas de emendas que tendam a abolir os direitos e garantias fundamentais, mas que seria possível a sua restrição, desde que não importe em eliminação ou esvaziamento (LENZA, 2009, p. 415).

Contudo, qualquer restrição ou diminuição do direito à vida terá como consequência a sua eliminação, haja vista que este direito não permite meio termo. $\mathrm{Ou}$ se tem direito à vida, e ao indivíduo se permite viver, ou inexiste direito à vida, e ao indivíduo impõe-se a morte.

Ademais, se o constituinte originário tivesse a intenção de estabelecer o momento em que o direito à vida passa a ser inviolável o teria feito, como fez com inúmeros dispositivos constitucionais garantidores de direitos fundamentais.

Tanto a definição de momento posterior à concepção como início da vida, quanto à legalização constitucional do aborto, implicariam um retrocesso social, o que é vedado no ordenamento jurídico pátrio.

No dizer de Canotilho:

O núcleo essencial dos direitos sociais já realizado e efetivado através de medidas legislativas deve considerar-se constitucionalmente garantido, sendo inconstitucionais quaisquer medidas estaduais que, sem a criação de outros esquemas alternativos ou compensatórios, se traduzam na prática numa 'anulação', 'revogação' ou 'aniquilação' pura e simples desse núcleo essencial. A liberdade do legislador tem como limite o núcleo essencial já realizado (1998, p. 81).

Dessa forma, entende-se pela impossibilidade de legalização do aborto ou definição de momento distinto da concepção para determinação do início à vida, frente ao sistema constitucional e legal adotado no Brasil.

Saliente-se, por oportuno, que recentemente o Supremo Tribunal Federal tratou da questão da utilização de embriões na pesquisa de células tronco, ao analisar a constitucionalidade da Lei de Biossegurança, na Ação Direita de Inconstitucionalidade n. 3.510-DF. 
Nesta ação, o Supremo Tribunal Federal parece ter se posicionado pelo início da vida com a formação do sistema nervoso central. No entanto, a ação não trata de aborto, mas da possibilidade de utilização de embriões que foram fertilizados e se encontram fora do corpo humano em pesquisas de células tronco, como é salientado nos próprios autos da ação.

Veja-se, neste sentido, o pronunciamento nos autos da ação citada da professora de genética Lenise Aparecida Martins Garcia:

Pesquisar células embrionárias obtidas de embriões congelados não é aborto. É muito importante que isso fique bem claro. No aborto, temos uma vida no útero que só será interrompida por intervenção humana, enquanto que, no embrião congelado, não há vida se não houver intervenção humana. É preciso haver intervenção humana para a formação do embrião, porque aquele casal não conseguiu ter um embrião por fertilização natural e também para inserir no útero. E esses embriões nunca serão inseridos no útero. É muito importante que se entenda a diferença (2010).

Assim, não podem ser utilizados os mesmos argumentos defendidos na alegação de constitucionalidade das pesquisas em embriões nas discussões acerca da legalização do aborto.

Ademais, em que pese o Supremo Tribunal Federal ter se inclinado no julgamento da ação supracitada ao reconhecimento do início da vida no momento da formação do sistema nervoso central, restou demonstrado que tal posição não possui respaldo na interpretação sistemática da Constituição e de sua conjugação com os tratados internacionais sobre direitos humanos ratificados pelo Brasil.

\section{CONSIDERAÇÕES FINAIS}

De todo o exposto, podemos concluir que, atualmente, é impossível a legalização do aborto no Brasil, tanto por lei infraconstitucional quanto por emenda à Constituição.

Isto porque existe norma supralegal definindo que a vida se inicia a partir da concepção e tal disposição não pode ser afrontada por normas infraconstitucionais. 
Além disso, a propositura de emenda constitucional que buscasse legalizar o aborto ou modificar para momento posterior à concepção o reconhecimento do direito à vida encontraria impedimento no núcleo irrestringível da Constituição e na vedação de retrocesso social.

Sendo assim, qualquer posição dos legisladores ou julgadores pátrios pela legalização do aborto padece do vício de inconvencionalidade, por afrontar tratado internacional de direitos humanos ratificado no Brasil, e inconstitucionalidade, por se opor à norma fundamental do ordenamento jurídico nacional.

Somente por uma nova Constituição Federal, portanto, é que seria possível a legalização do aborto no âmbito nacional.

\section{REFERÊNCIAS BIBLIOGRÁFICAS}

BRASIL. Código Penal. São Paulo: Editora Saraiva, 2009.

Constituição da República Federativa do Brasil. São Paulo: Editora Rideel, 2010.

Lei n. 9.434, de 4 de fevereiro de 1997. Dispõe sobre a remoção de órgãos, tecidos e partes do corpo humano para fins de transplante e tratamento e dá outras providências. Disponível em <http://www.planalto.gov.br/ccivil_03/leis/19434.htm>. Acesso em 01 de julho de 2011.

Supremo Tribunal Federal. Ação Direta de Inconstitucionalidade n. 3.510. Min. Rel. Ayres Britto, DJ 28/05/2010.

Supremo Tribunal Federal. Recurso Extraordinário n. 466.343-1. Min. Rel. Cezar Peluso, DJ 04/06/2009.

CANOTILHO, Joaquim José Gomes. Constitucional e teoria da constituição. Coimbra, 1998.

LENZA, Pedro. Direito Constitucional Esquematizado. São Paulo: Saraiva, 2009. 
NOVELINO, Marcelo. Direito Constitucional. São Paulo: Editora Método, 2008. 